\title{
Competências do empreendedor: Uma análise com empreendedores que vivenciaram o insucesso empresarial
}

\author{
Entrepreneur's competences: An analyses with entrepreuneurs who experienced busi- \\ ness failure
}

Italo Fernando Minello

Universidade Federal de Santa Maria

E-mail: italo.minello@uol.com.br

Laura Alves Scherer

Universidade Federal de Santa Maria

Leticia da Costa Alves

Universidade Federal de Santa Maria

Recebido em 23 de novembro de 2011. Aprovado em 19 de outubro de 2012

Editor Responsável: Edson Roberto Scharf, Dr.

Processo de avaliação por double blind review

\begin{abstract}
Resumo
O presente trabalho tem como proposta analisar as competências presentes em empreendedores antes, durante e depois do insucesso empresarial. Trata-se de um estudo descritivo e exploratório com seis empreendedores que tiveram seus negócios descontinuados. O conceito de competências adotado é o de Fleury e Fleury (2001) - um saber agir responsável e reconhecido, que implica mobilizar, integrar, transferir conhecimentos, recursos e habilidades que agreguem valor econômico à organização e valor social ao indivíduo - o qual foi analisado nas entrevistas dos empreendedores através da técnica de análise de conteúdo. As categorias escolhidas a priori foram: saber agir e saber comunicar, saber mobilizar recursos, saber engajar-se, comprometerse e assumir responsabilidades e saber aprender e ter visão estratégica. Como resultado deste estudo, pode-se evidenciar que as competências parecem influenciar o comportamento do empreendedor,
\end{abstract}

repercutindo no sucesso ou fracasso de sua organização. Essas competências foram analisadas em três momentos distintos de pesquisa, antes, durante e depois do insucesso empresarial. Antes do insucesso empresarial, as competências emergem como forma de desenvolvimento pessoal e profissional; Durante o insucesso empresarial, as competências não se apresentam com tanta frequência, ou são ausentes; E no período após o insucesso empresarial, essas competências ressurgem como forma de superar a adversidade.

Palavras-chave: Competência. Empreendedor. Insucesso Empresarial

\footnotetext{
Abstract

This paper aims to analyze the competences found in entrepreneurs before, during and after business failure. This is a descriptive study with six entrepreneurs who have discontinued their business. The concept of competence adopted is - to know how to
} 
act responsibly that means to mobilize, integrate, transfer knowledge, skills and resources that add economic value to the organization and social value to the individual (FLEURY AND FLEURY, 2001)which was analyzed in the interviews of entrepreneurs through the technique of content analysis. The categories were chosen a priori: know how to act and to communicate, know how to mobilize resources, know to engage and take responsibility and know to learn and have a strategic vision. As a result of this study, we can show that the competences seem to influence the entrepreneur's behavior, reflecting the success or failure of your organization. These competences were analyzed in three separate stages of research: before, during and after business failure. Prior to business failure, competences emerged as a form of personal and professional development; During business failure, competences did not come so often, or were absent, and the period after business failure, these competences resurface as a way to overcome adversity.

Keywords: Competences. Entrepreneur. Business Failure

\section{Introdução}

Os resultados fornecidos pela pesquisa GEM (2010), mostram um panorama do cenário da atividade empreendedora no Brasil. Estes resultados evidenciam alguns aspectos que parecem mapear a postura das organizações e, por consequência, dos empreendedores que as conduzem. Uma desses aspectos é a importância dos ativos intangíveis na vida profissional, como uma condição para a capacitação e a qualificação para formar um empreendedor. Esta formação o prepara para aprender a agir e pensar por conta própria, com criatividade liderança e visão de futuro, para inovar e ocupar o seu espaço no mercado, bem como adquirir conhecimento e desenvolver comportamentos, objetivando a baixar a taxa de mortalidade das empresas.

Além de sua formação, o comportamento do empreendedor pode estar atrelado a características subjacentes que emergem no contexto profissional. Estas singularidades de comportamento, no ambiente empresarial, se traduzem em forma de competências (ZARIFIAN, 2001; LENZI, 2008).
Nessa perspectiva, Filion e Lima (2010) destacam a ideia de que o desenvolvimento dos estudos sobre empreendedorismo deve ser feito não apenas por pesquisas da ação empreendedora, mas também do pensamento empreendedor e da ligação entre esses conceitos. Nesse sentido, percebe-se a relevância de estudos que busquem compreender características comportamentais do indivíduo empreendedor, no intuito de contribuir para o entendimento de quais competências podem ser relacionadas aos empreendedores diante do sucesso ou fracasso de seus negócios.

O presente artigo se concentrará no insucesso empresarial, em função de que este tema ainda é pouco explorado na literatura sobre negócios (FLECK, 2009; SINGH CORNER E PAVLOVICH, 2007, CARDON et al. 2012) e nas competências dos empreendedores diante dele.

Frente a esse contexto, o sucesso ou insucesso de uma organização pode estar atrelado tanto a aspectos comportamentais do gestor, quanto a aspectos internos da organização e externos do ambiente ao qual ela está inserida. (ZACHARAKIS, MEYER E DECASTRO, 1999; MINELLO, 2010). No que tange aos aspectos comportamentais, os resultados podem depender das características e competências do indivíduo que está gerindo a empresa. Esta abordagem está alinhada com a atividade de empreendedores que, com suas características e competências peculiares, buscam o melhor desempenho para o seu negócio decidindo sobre o futuro do seu empreendimento (FLEURY E FLEURY, 2001). Se, por ventura estas características e competências não estiverem presentes ou não forem as mais adequadas, o resultado organizacional, provavelmente não será o esperado, podendo levar o seu negócio à descontinuidade.

O insucesso empresarial na visão de Dotlich e Cairo (2003), Finkelstein (2007), Singh Corner e Pavlovich (2007), de uma forma ou de outra está associado as deci- 

sarial

sões e ao comportamento que este indivíduo tem na condução de seu empreendimento. Dessa forma, as características empreendedoras que influenciam o comportamento e as competências necessárias para o empreendedor parecem estar intimamente relacionadas, repercutindo no comportamento da organização.

A partir desta perspectiva, o presente trabalho tem por objetivo analisar as competências presentes em empreendedores antes, durante e depois do insucesso empresarial. Trata-se de um estudo descritivo e exploratório realizado com empreendedores que vivenciaram a descontinuidade de seu negócio. O conceito de competências adotado para este estudo é o de Fleury e Fleury (2001), pág. 188 - "um saber agir responsável e reconhecido, que implica mobilizar, integrar, transferir conhecimentos, recursos e habilidades que agreguem valor econômico à organização e valor social ao indivíduo" - o qual foi analisado nas entrevistas dos empreendedores através da técnica de análise de conteúdo. As categorias escolhidas a priori foram: saber agir e saber comunicar, saber mobilizar recursos, saber engajar-se, comprometer-se e assumir responsabilidades e saber aprender e ter visão estratégica.

\section{Competências do empreendedor}

O conceito de empreendedor evoluiu com o decorrer do tempo, acompanhando as transformações econômicas. Sua definição perpassa por diversos aspectos, dependendo da abordagem conceitual adotada. Para Filion (1999), o empreendedor é um indivíduo criativo, que tem capacidade de delimitar e atingir objetivos e que está sempre atento as oportunidades do ambiente. Dornelas (2008) também evidencia a identificação de oportunidades no conceito de empreendedor, acrescentando os riscos calculados, a iniciativa, a paixão pelo que faz e a capacidade de maximizar os recursos disponíveis de forma criativa. Já na abordagem de Hisrich, Peters e Shepherd (2009), o empreendedor é considerado um indivíduo que alia sua experiência ao seu conhecimento, buscando otimizar os recursos existentes para transformar ou inovar uma situação prática, aceitando as consequências de suas ações e assumindo os riscos necessários.

Ressalta-se que nas definições apresentadas acima, o empreendedor é um indivíduo dotado de características peculiares que os definem. Dentre tais características, Bueno, Leite e Pilatti (2004), destacam a predisposição para aprender, a busca pelo autoconhecimento, a atualização e a adaptação ao meio em que atua. Dornelas (2008) amplia essa perspectiva inserindo a visão de futuro, tomada de decisão coerente, exploração de oportunidades, determinação e dinamismo, dedicação, otimismo e paixão pelo que faz, independência, liderança, bons relacionamentos, organização, planejamento, conhecimento, aceitação de riscos calculados e criação de valor para a sociedade, enfatizando-as como as características mais relevantes para que os empreendedores tenham condições adequadas para aproveitar as oportunidades que o mercado apresenta.

Para Hisrich, Peters e Shepherd (2009) as características de empreendedores podem ser consideradas como a habilidade em executar, adaptar de modo cognitivo e aprender com o fracasso. Na visão de Zarifian (2001), as características empreendedoras estão relacionadas às competências dos empreendedores, pois no ambiente empresarial estas singularidades de comportamento se traduzem em forma de competências. $\mathrm{O}$ autor relata ainda que a competência considera o trabalho não apenas como atividades predefinidas, visto que o ambiente é mutável, mas sim como uma forma de assumir um pensamento reflexivo e assumir responsabilidades. Neste sentido, o trabalho não se configura mais como um conjunto de tarefas associadas ao cargo, torna-se, contudo, um prolongamen- 
to direto da competência que o indivíduo necessita mobilizar para atender a este ambiente em constante mutação.

Ainda sobre esta temática, as competências focadas no empreendedor e considerando-se as peculiaridades inerentes a cada indivíduo, pode-se relacionar estas às suas características enquanto empreendedores. Sob esta perspectiva, Paiva Júnior,
Leão e Mello (2003), tendo por base os estudos de Man e Lau (2000), destacam as seguintes competências empreendedoras: de oportunidade, de relacionamento, conceituais, administrativas, estratégicas e de comprometimento. Estas competências estão descritas no quadro 1 .

Quadro 1 - Competências empreendedoras

\begin{tabular}{|l|l|}
\multicolumn{1}{c}{$\begin{array}{c}\text { Competências } \\
\text { Empreendedoras }\end{array}$} \\
\hline $\begin{array}{l}\text { Competência de } \\
\text { oportunidade }\end{array}$ & Identificar, avaliar e buscar oportunidade no mercado. \\
\hline $\begin{array}{l}\text { Competência de } \\
\text { relacionamento }\end{array}$ & $\begin{array}{l}\text { Capacidade de criar uma imagem que transmita confiança; ter uma boa reputação; com- } \\
\text { promisso e conduta junto a redes de relacionamentos com parceiros efetivos e potenciais. }\end{array}$ \\
\hline $\begin{array}{l}\text { Competências } \\
\text { conceituais }\end{array}$ & $\begin{array}{l}\text { Capacidade de avaliar situações de risco que surgem em decorrência de suas ações em } \\
\text { qualquer ambiente. }\end{array}$ \\
\hline $\begin{array}{l}\text { Competências } \\
\text { administrativas }\end{array}$ & Eficiente alocação de talentos, recursos físicos, financeiros e tecnológicos. \\
\hline $\begin{array}{l}\text { Competências } \\
\text { estratégicas }\end{array}$ & $\begin{array}{l}\text { Visualizar panoramas a longo e médio prazos alcançáveis e realistas; Deve ser apto a } \\
\text { perceber tendências emergentes no ambiente, sintonizar-se com informações diversas e } \\
\text { perceber a direção das forças ambientais. }\end{array}$ \\
\hline $\begin{array}{l}\text { Competências de } \\
\text { comprometimento }\end{array}$ & Habilidade de manter a dedicação, principalmente em situações adversas. \\
\hline
\end{tabular}

Fonte: Desenvolvido pelos autores com base em Paiva Júnior, Leão e Mello (2003).

No que diz respeito à literatura sobre competências, pode-se observar, segundo Dutra (2004), que existem várias definições para o termo, assim como distintas abordagens; no entanto, estes diferentes prismas podem ser considerados complementares. $\mathrm{O}$ autor relacionou os vários conceitos de competência encontrados em duas linhas, as quais preconizam de um lado a competência como um conjunto de conhecimentos, habilidades e atitudes necessárias para a pessoa exercer seu trabalho e, de outro, as competências entendidas como a entrega da pessoa para a organização. Nesse sentido, pode-se entender competência como a ação que combina e agiliza as capacidades e os recursos tangíveis, quando os mesmos forem necessários. A partir disso, o autor constata que a competência é um conjunto de capacidades e não apenas um conjunto de tarefas referentes a um cargo.

Mussak (2003) considera competência como a capacidade que um indivíduo tem de resolver problemas e alcançar as metas estabelecidas, sugerindo então, uma relação entre competência e resultado organizacional. Sendo assim, o autor relata que a "competência é diretamente proporcional ao resultado obtido, mas é inversamente proporcional ao tempo consumido para atingi-lo e ao volume de recursos utilizados" (MUSSAK, 2003, p. 53).

Já na visão de Le Boterf (1998), as competências podem ser entendidas como um saber agir responsável que, por meio da mobilização, articulação, transferência e integração de recursos (conhecimentos, capacidades), em uma situação profissional específica. Dessa forma, a competência 
Competências do empreendedor: Uma análise com empreendedores que vivenciaram o insucesso empresarial

surge na ação do indivíduo e não existe antes dela.

Para Fleury e Fleury (2001) a palavra competência tem sido utilizada para designar um indivíduo qualificado para desenvolver alguma atividade, ressaltando que o seu oposto não implica apenas na ausência dessa capacidade, mas também traz consigo um sentimento pejorativo e depreciativo. Os autores definem competência, a partir da linha de raciocínio de-

Quadro 2: Competências senvolvida por Le Boterf (1995), como "um saber agir responsável e reconhecido, que implica mobilizar, integrar, transferir conhecimentos, recursos e habilidades que agreguem valor econômico à organização e valor social ao indivíduo" (FLEURY e FLEURY, 2001, p.188). Destaca-se que tais competências são elencadas no quadro 2.

\begin{tabular}{|l|l|}
\multicolumn{2}{|c|}{ Competência } \\
\hline Saber agir & $\begin{array}{l}\text { Saber o que e por que faz } \\
\text { Saber julgar, escolher, decidir. }\end{array}$ \\
\hline $\begin{array}{l}\text { Saber mobilizar } \\
\text { recursos }\end{array}$ & Criar sinergia e mobilizar recursos e competências. \\
\hline Saber comunicar & Compreender, trabalhar, transmitir informações, conhecimentos. \\
\hline Saber aprender & Trabalhar o conhecimento e a experiência, rever modelos mentais, saber desenvolver-se. \\
\hline $\begin{array}{l}\text { Saber engajar-se } \\
\text { e comprometer- } \\
\text { se }\end{array}$ & Saber empreender, assumir riscos, comprometer-se. \\
\hline $\begin{array}{l}\text { Saber assumir } \\
\text { responsabilidades }\end{array}$ & $\begin{array}{l}\text { Ser responsável, assumindo os riscos e consequências de suas ações e sendo por isso } \\
\text { reconhecido. }\end{array}$ \\
\hline $\begin{array}{l}\text { Ter visão estraté- } \\
\text { gica }\end{array}$ & $\begin{array}{l}\text { Conhecer e entender o negócio da organização, o seu ambiente, identificando oportuni- } \\
\text { dades e alternativas. }\end{array}$ \\
\hline
\end{tabular}

Fonte: Fleury e Fleury (2001).

A partir do levantamento dos pressupostos teóricos da abordagem sobre competência, adotou-se para este artigo o conceito de competência apresentado no quadro 2, de Fleury e Fleury (2001), por se tratar de um modelo teórico consolidado na literatura sobre o tema.

Com base no exposto até então, e sabendo que as características dos empreendedores influenciam nas suas competências, pode-se dizer que, aparentemente, se essas características não forem as mais adequadas, ou apresentarem fatores descarriladores, tais como a arrogância (FINKELSTEIN, 2007), as competências também podem ser afetadas. E, sabendo que essas competências influenciam no desempenho organizacional, pode-se dizer que isso poderá acarretar na descontinuidade do negócio. Destarte, abordam-se nos itens subsequentes, as abordagens teóricas sobre insucesso empresarial e sua relação com competências de empreendedores.

\section{Insucesso empresarial}

Para Zacharakis, Meyer e DeCastro (1999), Fleck (2009) e Cardon et al. (2012), a maioria dos estudos organizacionais de novos empreendimentos focaliza em casos "de sucesso", tendo sido limitadas as pesquisas sobre fracassos de empreendimentos por diversas razões. Primeiro, é difícil realizar análise financeira de empreendimentos fracassados, visto que seus dados financeiros geralmente não estão publicados, tornando difícil a localização dos empreendedores que vivenciaram esta 
situação (ZACHARAKIS, MEYER e DECASTRO, 1999).

Por outro lado, Robinson (2007) considera que o fracasso nos negócios representa um aspecto importante da economia a ser estudado, no entanto são de difícil análise devido à grande variedade de definições de fracasso nos negócios, às suas diversas causas de encerramento e à falta de dados abrangentes. Segundo o autor, estudar este tema é complexo e difícil em função de diversos fatores que influenciam os empreendedores a descontinuarem suas operações, tais como aposentadoria, venda do negócio, falência, erros gerenciais, ações e comportamentos inadequados dos donos do negócio. Para complicar ainda mais, existe a questão de como definir insucesso das empresas. Embora um negócio que acabe em falência seja, sem dúvida, um insucesso, outros negócios nãolucrativos podem ser encerrados antes da falência, mas provavelmente poderiam ser categorizados como um insucesso.

A partir do raciocínio desenvolvido por Fleck (2009), na visão de Mellahi e Wilkinson (2004), a literatura oferece diferentes concepções de insucesso empresarial, como: mortalidade organizacional, morte organizacional, saída organizacional, falência, declínio, redução e downsizing.

$\mathrm{Na}$ visão de Hisrich, Peters e Shepherd (2009), o insucesso empresarial dá-se quando há uma queda na receita e/ou um acréscimo nas despesas de grandes proporções, tornando a empresa insolvente e delimitando a possibilidade de atrair financiamentos de dívidas ou patrimônio liquído. Os autores ressaltam ainda, que a descontinuidade é comum entre empresas empreendedoras, pois estas têm sua base na inovação, no novo, o que traz consigo a incerteza e condições oscilantes advindas com essa novidade.

Bruno, Mcquarrie e Torgrimson (1992) consideram que o fracasso do negócio, pode ter várias causas, incluindo problemas legais, disputas na sociedade, morte ou simplesmente uma mudança de interesses. Dessa forma, no intuito de definir um conceito que envolva diferentes causas para o insucesso, os autores definiram insucesso empresarial como descontinuidade do negócio. McGrath (1999) parece concordar com esses autores sugerindo que um empreendimento fracassou quando é descontinuado como consequência de um desempenho real ou previsto inferior a um limiar mínimo. Em outras palavras, o fracasso é o término de uma iniciativa que não atingiu seus objetivos. Para esta pesquisa, será adotado o conceito de insucesso empresarial como descontinuidade do negócio, apresentado por Bruno, Mcquarrie e Torgrimson, por este se adequar ao objeto de estudo. Essa definição abrange não apenas fatores econômicos, como falência e insolvência, mas também fatores como disputas irremediáveis, problemas legais e questões pessoais do empreendedor.

Com relação às causas que levam a descontinuidade de um empreendimento, pode-se perceber que estão atreladas tanto a aspectos comportamentais, quanto a aspectos internos e também aos aspectos externos a empresa. Para este estudo, serão focadas as causas comportamentais, tendo em vista que tem como foco analisar as competências dos empreendedores diante do insucesso do seu negócio e que tais competências estão atreladas as características e comportamentos dos empreendedores.

\section{Relação entre competências e insuces- so empresarial}

No momento em que o empreendedor é questionado sobre os motivos pelos quais ele fracassou nos negócios, percebe-se com certa frequência, de acordo com Pereira (1995), que seus relatos evidenciam que a responsabilidade por seu insucesso é do governo, do momento econômico, da falta de cliente, deslealdade dos sócios, da concorrência sem ética, dos juros bancários, da 

sarial

carga tributária, dentre vários outros fatores externos ao negócio. Na visão de pereira (1995), Shepherd (2003), Shepherd e Cardon (2009), parece haver certa falta de visão por parte dos empreendedores que culpam terceiros pelo seu fracasso. Essa falta de visão é relacionada com seus próprios erros quando eles não querem reconhecer suas falhas, quando acreditam estarem certos a respeito de tudo o que acontece em seu redor e culpar terceiros é um estilo de enfrentamento utilizado como forma de defesa psicológica que parece mascarar a realidade. As variáveis ambientais são as mesmas para todos os negócios no mercado, respeitando-se as respectivas peculiaridades de mercado de cada empreendimento. Da mesma forma, as dificuldades, as ameaças e as oportunidades também são as mesmas, no entanto, algumas empresas obtêm sucesso e outras não. $\mathrm{Na}$ visão de Pereira (1995), o que difere o sucesso do fracasso são as características, capacidades e habilidades pessoais do empreendedor, focalizadas nesse estudo pelas competências do empreendedor.

Para Fleury e Fleury (2001) as competências ajudam a organização manter um alto nível de desempenho no mercado, sendo que os melhores resultados estão atrelados à inteligência e a personalidade das pessoas, destacando assim, a influência dos aspectos comportamentais dos empreendedores no sucesso ou insucesso empresarial. Nesse sentido, caso as características empreendedoras que, se referem às singularidades de comportamento que se transformam em competências (ZARIFI$A N, 2001)$ não se evidenciem no sentido de contribuir para uma boa gestão, pode-se dizer que o desempenho organizacional será afetado, podendo ocasionar a descontinuidade do negócio.

Sob essa perspectiva, Minello (2010) salienta que embora estas competências estejam presentes nos empreendedores, a percepção do indivíduo em uma situação de adversidade difere dos momen- tos de sucesso, podendo afetar sua capacidade de avaliação para a tomada de decisão. Shepherd (2003), Shepherd e Cardon (2009), Ucbasaran (2010), Cardon et al. (2012) , complementam que o insucesso pode desencadear uma resposta emocional negativa que influenciam no desempenho do empreendedor.

\section{Metodologia}

O presente estudo caracteriza-se como uma pesquisa qualitativa do tipo descritivo e exploratório, tendo como objetivo analisar as competências presentes em empreendedores antes, durante e depois do insucesso empresarial.

A abordagem qualitativa justificase por ser adequada a situações que buscam compreender aspectos psicológicos, relacionados ao fenômeno em estudo (RICHARDSON, 1985). A pesquisa descritiva visa medir ou coletar informações de maneira independente ou conjunta sobre os conceitos e variáveis a que se referem (SAMPIERI, 2006). Quanto à pesquisa exploratória, serve para examinar um tema que foi pouco estudado, ou não foi abordado antes (SAMPIERI, 2006), como parece ser a análise de competências em empreendedores que vivenciaram o insucesso.

Para atender a problemática e objetivos propostos, compõem a unidade de análise do presente estudo seis empreendedores da Grande São Paulo que descontinuaram seus negócios. O contato foi estabelecido por meio de escritórios de advocacia e de contabilidade que auxiliaram no processo de descontinuidade dos negócios de seus clientes. Devido o tema insucesso empresarial ser imbuído de emoções e sentimentos, foi difícil o acesso aos empreendedores que estivessem preparados e predispostos a dividir suas experiências. Por isso optou-se como critério os empreendedores que vivenciaram o insucesso e conseguiram superá-lo. Essa superação pode ter sido uma mudança de carreira profissi- 
onal, a criação e desenvolvimento de um novo empreendimento, ou alguma outra atividade em que a pessoa em questão tenha alcançado satisfação pessoal e profissional. Nesta pesquisa, estes empreendedores são tratados como E1 para o Entrevistado 1, E2 para o Entrevistado 2 e assim, sucessivamente.

Com relação à coleta de dados fezse uso de entrevistas semi-estruturada, por meio da aplicação de um roteiro que permitiu o levantamento de dados nos diferentes momentos de pesquisa - antes, durante e depois do insucesso empresarial. Tais entrevistas tiveram duração de uma hora e trinta minutos, em média, e foram realizadas em locais de preferência do entrevistado, gravadas, transcritas e posteriormente analisadas.

Quanto à análise dos dados, aplicou-se a técnica de análise de conteúdo e foram definidas categorias a priori. De acordo com Bardin (2011, p. 48) a análise de conteúdo é:

"um conjunto de técnicas de análise das comunicações visando obter, por procedimentos, sistemáticos e objetivos de descrição do conteúdo das mensagens, indicadores (quantitativos ou não) que permitam a inferência de conhecimentos relativos às condições de produção/recepção (variáveis inferidas) destas mensagens".

As categorias de análise foram definidas a priori a partir das concepções de Fleury e Fleury (2001) sobre competências, referenciadas no quadro 2 . As categorias foram definidas a partir do agrupamento de algumas competências em função de que sua análise conjunta facilita o entendimento do objetivo proposto, por meio do raciocínio desenvolvido na análise de cada categoria. A ideia de agrupar as competências se deu em função de sua complementaridade conceitual, como por exemplo:

Saber agir e saber comunicar - O saber comunicar está intrinsicamente relacionado ao saber agir, pois a capacidade que o indivíduo tem de agir dentro da organização, depende de como ele compreende o contexto organizacional e a forma como ele transmite essa compreensão.

Saber engajar-se, comprometer-se e assumir responsabilidades - Ambas competências apontam a questão de assumir riscos. Para agir de tal maneira, o indivíduo necessita estar comprometido de forma responsável para alcançar os objetivos da organização.

Saber aprender e ter visão estratégica - a aprendizagem visa uma mudança de modelo mental que por consequência contribui para o aumento de visão estratégica. Nesse sentido, a medida que o indivíduo vai trabalhando o conhecimento e a experiência, vai desenvolvendo-se e entendendo o negócio da organização, identificando oportunidades e alternativas.

O termo adotado para ambas as concepções foi tratado neste estudo como "competência". Das sete competências apresentadas, foram escolhidas quatro categorias, tendo em vista a coerência com o objetivo deste estudo. Apresenta-se a seguir o quadro $3 \mathrm{com}$ as categorias de análise definidas para este trabalho.

Quadro 3: Categorias de análise a priori 
Competências do empreendedor: Uma análise com empreendedores que vivenciaram o insucesso empresarial

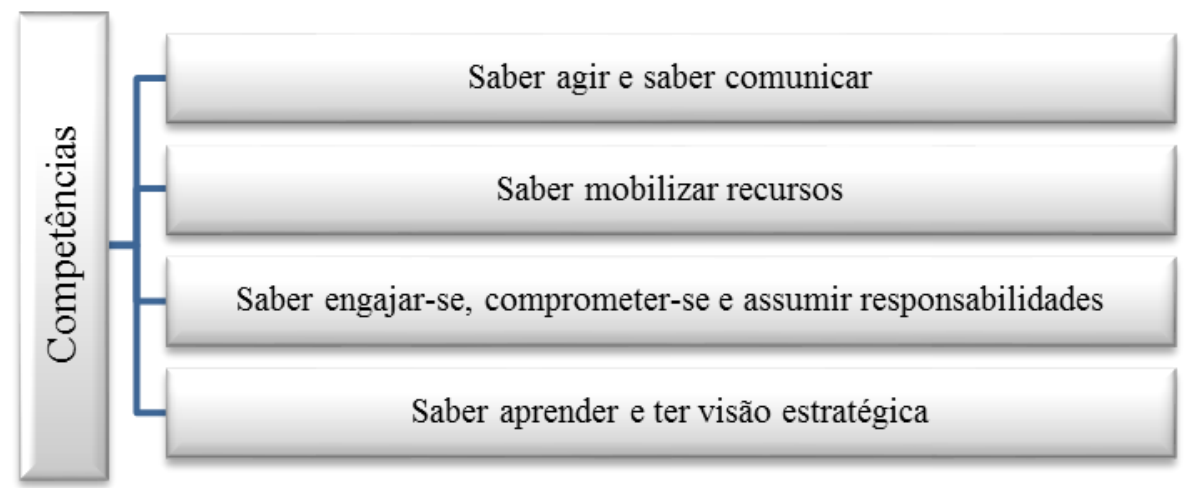

Fonte: Elaborado pelos autores

Nas entrevistas realizadas, buscou-se identificar as competências presentes nos empreendedores, antes, durante e depois do insucesso empresarial e verificar se houve alteração dessas competências nesses três períodos. Sendo assim, as análises foram assim efetuadas:

1) Caracterização dos Empreendedores Entrevistados

2) Caracterização das Competências dos Empreendedores - antes, duran- te e depois do insucesso empresari$\mathrm{al}$;

3) Análise das Categorias a priori, por meio da técnica da análise de conteúdo.

\section{Apresentação e análise dos dados}

Primeiramente foi realizada a caracterização dos empreendedores entrevistados, apresentada no quadro 4 :

Quadro 4: Caracterização dos empreendedores entrevistados

\begin{tabular}{|c|c|c|c|c|c|c|c|}
\hline \multirow{2}{*}{ 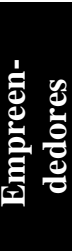 } & \multicolumn{3}{|c|}{$\begin{array}{c}\text { Dados Referentes à Biogra- } \\
\text { fia } \\
\text { dos Entrevistados }\end{array}$} & \multicolumn{4}{|c|}{$\begin{array}{c}\text { Dados Referentes ao Insucesso } \\
\text { Empresarial }\end{array}$} \\
\hline & Idade & Gênero & Formação & Duração & $\begin{array}{l}\text { Segmento do } \\
\text { Negócio }\end{array}$ & $\begin{array}{c}\text { Fatores de insucesso } \\
\text { relacionados às compe- } \\
\text { tências }\end{array}$ & $\begin{array}{l}\text { Atividade } \\
\text { atual }\end{array}$ \\
\hline E1 & 49 & $\mathrm{~F}$ & $\begin{array}{l}\text { Superior } \\
\text { Incompleto }\end{array}$ & 7 anos & $\begin{array}{l}\text { Serviço de } \\
\text { transporte de } \\
\text { cargas }\end{array}$ & $\begin{array}{l}\text { Gastar demais } \\
\text { Falta de conhecimento das } \\
\text { práticas administrativas } \\
\text { Operações mal feitas } \\
\text { Clientes insatisfeitos } \\
\text { Falta de experiência, adminis- } \\
\text { tração, habilidade para geren- } \\
\text { ciar }\end{array}$ & $\begin{array}{l}\text { Empresária no } \\
\text { segmento de } \\
\text { transportes de } \\
\text { cargas (outra } \\
\text { empresa) }\end{array}$ \\
\hline E2 & 49 & $\mathrm{~F}$ & $\begin{array}{l}\text { Superior } \\
\text { Completo } \\
\text { em Direito }\end{array}$ & 3 anos & $\begin{array}{l}\text { Serviço de } \\
\text { transporte de } \\
\text { cargas }\end{array}$ & $\begin{array}{l}\text { Falta de profissionalismo do } \\
\text { sócio e o não envolvimento } \\
\text { com a atividade } \\
\text { Fazer uso do nome da empresa } \\
\text { em benefício próprio (sócio) } \\
\text { Desentendimento na sociedade } \\
\text { para o fechamento da empresa }\end{array}$ & $\begin{array}{l}\text { Proprietária } \\
\text { de uma pou- } \\
\text { sada e profes- } \\
\text { sora universi- } \\
\text { tária }\end{array}$ \\
\hline $\mathbf{E 3}$ & 55 & M & $\begin{array}{l}2^{\circ} \mathrm{Grau} \\
\text { Incompleto }\end{array}$ & 6 anos & $\begin{array}{l}\text { Indústria de } \\
\text { cosméticos }\end{array}$ & $\begin{array}{l}\text { Relacionamento dos sócios - } \\
\text { dificuldade de diálogo } \\
\text { Falta de capacidade de geren- } \\
\text { ciar o negócio }\end{array}$ & $\begin{array}{l}\text { Proprietário } \\
\text { de uma indús- } \\
\text { tria de cosmé- } \\
\text { ticos }\end{array}$ \\
\hline
\end{tabular}




\begin{tabular}{|c|c|c|c|c|c|c|c|}
\hline & & & & & & $\begin{array}{l}\text { Falta de visão dos sócios } \\
\text { Desonestidade e desinteres- } \\
\text { se do sócio }\end{array}$ & $\begin{array}{l}\text { (outra empre- } \\
\text { sa) }\end{array}$ \\
\hline E4 & 49 & M & $\begin{array}{l}\text { Superior } \\
\text { Completo } \\
\text { em Admi- } \\
\text { nistra-ção }\end{array}$ & 2,5 anos & $\begin{array}{l}\text { Segmento } \\
\text { comercial, } \\
\text { design eletrô- } \\
\text { nico e infor- } \\
\text { mática }\end{array}$ & $\begin{array}{l}\text { Falta de planejamento } \\
\text { Não acompanhamento do } \\
\text { momento econômico } \\
\text { Confiar em pessoas erradas } \\
\text { Falta de capital de giro } \\
\text { Desestabilização societária } \\
\text { Assumir altos compromissos } \\
\text { Pouco conhecimento da } \\
\text { área técnica do negócio }\end{array}$ & $\begin{array}{l}\text { Proprietário } \\
\text { de postos de } \\
\text { combustível } 2 \\
\text { indústrias de } \\
\text { reciclagem e } 1 \\
\text { restaurante }\end{array}$ \\
\hline E5 & 56 & $\mathrm{M}$ & $\begin{array}{l}\text { Superior } \\
\text { Completo } \\
\text { em Música } \\
\text { e cursando } \\
\text { Artes Plás- } \\
\text { ticas }\end{array}$ & 10 anos & $\begin{array}{l}\text { Segmento } \\
\text { Editorial e } \\
\text { Comércio de } \\
\text { Jóias e Ouro }\end{array}$ & $\begin{array}{l}\text { Deixar de administrar o } \\
\text { negócio } \\
\text { Não sabia lidar com o dinhei- } \\
\text { ro; deslumbre } \\
\text { Não acreditar no trabalho } \\
\text { acadêmico de administração } \\
\text { Falta de conhecimento no que } \\
\text { está fazendo } \\
\text { Irresponsabilidade } \\
\end{array}$ & $\begin{array}{l}\text { Maestro de } \\
\text { orquestra, } \\
\text { Coordenador } \\
\text { de uma ONG } \\
\text { focada nas } \\
\text { artes e candi- } \\
\text { dato a verea- } \\
\text { dor } \\
\end{array}$ \\
\hline E6 & 87 & M & $\begin{array}{l}2^{\circ} \text { Grau } \\
\text { completo } \\
\text { Curso de } \\
\text { Negócios } \\
\text { nos } \\
\text { EUA }\end{array}$ & 48 anos & $\begin{array}{l}\text { Segmento de } \\
\text { engenharia de } \\
\text { obras públicas } \\
\text { e segmento de } \\
\text { coleta e reci- } \\
\text { clagem de lixo }\end{array}$ & $\begin{array}{l}\text { A empresa cresceu demais, } \\
\text { sem planejamento } \\
\text { A morte súbita de um sócio } \\
\text { Não pagamento de contratos } \\
\text { acordados, por parte da prefei- } \\
\text { tura de SP } \\
\text { Pegar recursos financeiros em } \\
\text { bancos; juros altos }\end{array}$ & $\begin{array}{l}\text { Divide um } \\
\text { renomado } \\
\text { escritório de } \\
\text { advocacia, e } \\
\text { cuida de seus } \\
\text { investimentos } \\
\text { financeiros }\end{array}$ \\
\hline
\end{tabular}

Fonte: Elaborado pelos autores.

Neste estudo, as categorias foram definidas a priori (quadro 3) e analisadas a seguir. Ressalta-se que estas categorias foram analisadas em três momentos distintos: antes, durante e depois do insucesso empresarial.

\subsection{Saber agir e saber comunicar}

A competência surge no momento em que o indivíduo executa uma ação específica, para desenvolver alguma atividade com qualificação (LE BOTERF, 1998; FLEURY, 2001). Uma das ações de empreendedores identificadas por Lenzi (2008) foi a forma de agir com persuasão junto à sua rede de contatos. Na visão destes autores parece estar de acordo com o relato dos entrevistados, exemplificado aqui por E1 no período anterior ao insucesso. O empreendedor parece qualificado e confiante para propor sociedade na sua rede de contatos, apresentando assim uma competência empreendedora de relaciona- mento (PAIVA JUNIOR, LEÃO e MELLO, 2003), conforme a seguir.

"Eu falei, ó vocês vende o ouro de vocês errado, e não é assim... Ai ele falou, como é que é isso, ai eu falei, poxa, tem que montar um laboratório... Aí monto sociedade com ele, e, a vida cresce outra vez. A vida cresce outra vez, cresce a vida, cresce sua área também né."( E5)

O foco da competência se movimenta para o momento da ação, para a combinação e a mobilização das capacidades, pois é ali que se afirma e se coloca a questão da competência (DIAS et al., 2008). Os empreendedores pesquisados revelaram muitos momentos que precisaram agir de acordo com as suas competências. Durante o insucesso, estas ações foram exemplificadas por E3, que primeiramente parece ter tentado utilizar suas competências no momento adequado para evitar ou minimizar o insucesso, mas, posteriormente, não se destacaram, pois pode-se 

sarial

perceber a falta de habilidade na condução do negócio, como pode ser visto no relato a seguir.

"Naquele momento se nós não tivéssemos feito aquilo tinha quebrado, não, naquele momento, se nós soubéssemos administrar, ai não teríamos quebrado. Não foi a empresa, a empresa foi beleza, os sócios é que pecaram, que é errado, a empresa ia embora, sabe?! Ia embora, que nem você por o carro na banguela, sem motorista, vai embora, mas nós dois erramos, não soubemos conduzir, sentar, conversar... Montar uma, uma planilha de trabalho, entendeu? Uma estratégia, pra organizar, e pra crescer entendeu?! Talvez eu não soubesse ficar atrás da mesa, administrando tudo, pra fazer precisa isso né?! Eu saia pra rua, saia pra rua o dia inteiro." (E3)

Para Dutra (2001), o conjunto de competências - conhecimento, habilidades e atitudes - é uma entrega de resultados voltados à inovação, renovação, criação, geração de novos negócios, desenvolvidos por meio de suas ações. Dentre esses resultados, ressalta-se a renovação e a geração de novos negócios, como no caso de E3, que após o insucesso, teve que buscar outras alternativas de negócio, como é evidenciado a seguir.

"Minha esposa começou a fazer pão integral, que ela sabe fazer, e eu comecei a vender cara, pra comer, não tinha, não tinha, não arrumava. E a comunidade adventista come muita coisa integral, pão integral. Então e, e minha esposa ela gosta muito de, de, de pão doce, pães, tortas, e começou a fazer isso e eu ia vendendo. Sexta feira eu ia pra porta da... É a escola e a Igreja do lado, sabe? É o colégio adventista e a igreja adventista. Aí eu ficava lá na porta de tarde, e o pessoal comprava né, pra levar pra casa, pro sábado. Porque adventista não faz nada no sábado, né?! Não cozinha, nada, prepara tudo na sexta. E eu vendia pros irmão, entregava nas casas, e era um dinheirinho que entrava, dava pra gente ir comendo. E pagando luz, água e comer." (E3)

A partir dos resultados encontrados nos três períodos vivenciados pelos empreendedores, pode-se perceber que suas ações não eram planejadas e eram definidas pela busca de resultados imediatos para o seu negócio, no intuito de enfrentar as adversidades encontradas (MINELLO, 2010; DOTLICH e CAIRO, 2003).

\subsection{Saber mobilizar recursos}

Dutra (2004) visualiza a competência como a ação que combina e agiliza as capacidades e os recursos tangíveis, quando os mesmos forem necessários. Nesse contexto, outro aspecto que merece destaque é a importância dos ativos intangíveis com foco no índivíduo, como a capacitação e a qualificação para formar o empreendedor (GEM, 2010). Esta formação o prepara para aprender a agir e pensar por conta própria, com criatividade liderança e visão de futuro, para inovar e ocupar o seu espaço no mercado, bem como adquirir conhecimento e desenvolver comportamentos, objetivando a baixar a taxa de mortalidade das empresas (GEM, 2010). Esta situação foi observada no relato dos entrevistados e está ilustrada no período anterior ao insucesso do E1.

"Então, administrar sem ter curso, sem ter formação administrativa, mais eu aprendi muito quando eu quebrei, porque você deve ganhar com uma mão e guardar na outra. É isso que você, o, o, o gestor bem sucedido age assim, primeiro você ganha com uma mão e segura com a outra e você não pode gastar além do que você ganha, então o que você tem que fazer você tem que ganhar 30, você tem que ganhar $30 \%$, daquilo que você ganhou, então o que você tem que fazer, acredito que hoje, pra você se dar bem, você tem que calcular todos os custos, calcular as despesas e o lucro né, por que hoje em dia você trabalha com a margem de lucro de 30 a $40 \%$. Você tirou, tira todas as despesas, você tem que ter um lucro ai de 15 a $20 \%$ liquido, né, pagamos as despesas, impostos, funcionários, tudo mais." (E1)

Na visão de Paiva Júnior, Leão e Mello (2003), o empreendedor necessita saber maximizar a criação de valor para empresa, sendo assim, aparenta ser relevante otimizar os recursos disponíveis, no intuito de atingir os objetivos propostos, o que caracteriza a mobilidade de recursos. Nesse sentido, parece haver uma seme- 
lhança entre as situações dos empreendedores entrevistados. No relato de E4 pode ser evidenciado, no período durante o insucesso, a ausência desta competência.

“Aí apertou bastante, eu já tava com uma despesa alta né, eu tava sozinho, tinha poucos representantes comerciais também, fazia a área de componentes, outros faziam a área de placas, e eu sei que eu fui me apertando financeiramente, a coisa foi estreitando, ai tivemos essa infelicidade né, e foi onde a empresa começou a entrar no vermelho, ai não consegui pagar o aluguel, a despesa do carro, já não conseguia suprir as necessidades da minha família, e até que eu infelizmente, finalmente, quebrei. Quebrei com divida alta, é... levei muitos anos ai, pra poder, numa faixa ai de uns cinco seis anos pra poder zerar o meu nome no mercado novamente, mas graças a Deus depois desse período ai conseguir restabelecer o nome a credibilidade, o crédito tudo, mas foi difícil.” (E4)

Para poder aproveitar as oportunidades adequadas e no caso de ter que enfrentar uma situação imprevista, um incidente, algo que não foi programado, o indivíduo precisa estar sempre mobilizando recursos para resolver as novas situações de trabalho (ZARIFIAN, 2001). Esta competência implica em saber como mobilizar, integrar e transferir os conhecimentos, recursos e habilidades. No caso de E3, após vivenciar a adversidade do insucesso empresarial, o empreendedor conseguiu mobilizar os recursos financeiros disponíveis para pagar suas dívidas, como pode ser visto no relato do período posterior ao insucesso, a seguir.

"Primeiro era financeiro porque, todo relacionamento com as empresas eu que fazia, comprava, pagava, vendia, entendeu?! E daí? E agora? Ficou, tinha conta pra pagar, e eu honrei com todas as contas. Depois de fechada a empresa, ainda ficou uns restos de mercadoria que foi vendida, e quando eu recebi eu paguei todo, eu paguei. Ninguém sabe disso, paguei todo mundo, paguei todos eles com juros, duas empresas que devia, empresa grande, embalagem, foi tudo pago, pago. Ficamos liso mas não fiquei devendo pra ninguém." (E3)

Assim, verifica-se que a mobilização de recursos e competências dos empre- endedores entrevistados concentra-se na busca por recursos financeiros, visto que a adversidade considerada neste artigo é o insucesso do seu negócio.

\subsection{Saber engajar-se, comprometer-se e assumir responsabilidades}

A dimensão do mundo do trabalho, de acordo com Dias et al., (2008), caracteriza-se pela necessidade de se incluir a instabilidade, o evento, a flexibilidade e a responsabilidade, como integrantes de um novo contexto empresarial. Nesse sentido, Ruano (2003) relata que as pessoas ao desenvolverem suas competências, transferem o seu conhecimento para a organização, dando-lhes condições para enfrentar novos desafios. Tendo por base estes aspectos, pode-se dizer que os indivíduos precisam buscar conhecimento antes de iniciarem em alguma atividade, pois assim terão maiores chances de se desenvolverem. Outro aspecto a ser destacado, resgatando-se os pressupostos teóricos de Dornelas (2008), dizem respeito às características dos empreendedores, as quais estão ligadas às competências. $\mathrm{O}$ autor coloca que, dentre outros aspectos, um empreendedor precisa ter conhecimento, dedicação e assumir riscos calculados. Estes aspectos podem ser relacionados a esta categoria, pois foram encontrados nas falas dos entrevistados, como se pode observar na fala de E2, no que diz respeito ao período antes do insucesso empresarial.

\footnotetext{
“A possibilidade de realização de coisas, da capacidade, então assim, eu posso talvez não ter a habilidade mas a capacidade eu tenho, e a habilidade eu desenvolvo. É uma questão, me lembro que me falavam assim: é uma questão de treinar, treinar, treinar.[...] A dedicação aquilo que você faz, se tiver que fazer, procura fazer bem feito, se tiver que fazer se dedique." (E2)
}

As pessoas competentes são chamadas em geral para encarar novos desafios e, na medida em que correspondem de maneira positiva, recebem desafios maio- 

sarial

res ainda (DUTRA, 2001). Nessa perspectiva, Mussak (2003) relata que um indivíduo responsável arca com as consequências dos seus próprios atos. $\mathrm{O}$ autor afirma também que assumir responsabilidades inclui admitir os deméritos de um fracasso, assim como compartilhar um sucesso. A responsabilidade emerge assim, como uma competência na qual o indivíduo empreendedor tem de responder pelos seus atos, arcando com as consequências. Neste estudo, uma das consequências que se pode observar é a descontinuidade do negócio. Esses aspectos podem ser identificados na fala de E6 durante o insucesso.

“[...] perdemos algumas dezenas de milhões de dólares, ainda perdemos, mais eu vi que o negocio era vender a empresa. Isso foi uma das coisas mais brutais, que um ser humano pode passar em matéria profissional, porque você de uma vida profissional maravilhosa, só de êxito de repente você vê, aquilo se desmoronar, como um castelo de areia e o negócio, se eu não consigo vender... eu vendi... eu fechei o negócio no primeiro semestre de 1992, a concordata foi de 1990." (E6)

Para Paiva Júnior, Leão e Mello (2003), os empreendedores devem saber assumir os riscos decorrentes de suas ações em qualquer ambiente, comprometendo-se com as consequências que virão. Nesse sentido, cabe ao empreendedor, que vivenciou o fracasso da sua empresa, identificar novas oportunidades, tentar se reerguer e superar esta adversidade, comprometendose com o seu desenvolvimento pessoal. Nos relatos dos entrevistados, pode-se evidenciar que estes conseguiram superar a descontinuidade de seus empreendimentos, comprometendo-se com uma nova atividade que lhes proporcionasse satisfação emocional, como se pode observar no trecho da fala de E1, depois do insucesso.

\footnotetext{
"Eu tinha uma casa na zona leste, e eu peguei essa casa troquei no mercado, fiz uma troca. Eu mexia com transporte, de repente eu fui mexer com mercadinho, não entendia nada, mas eu fiquei 11 meses com o mercado e me dei bem, só que eu botei um sócio, e o sócio me passou a perna, e eu quebrei
}

junto com o mercado também, resultado, fiquei de novo numa situação difícil, por pouco tempo. Daí o que eu fiz, agora eu to achando que devo voltar pra mercado de transporte. E falei só que eu to sem dinheiro, a casa eu dei no mercado, preciso ver o que eu vou fazer, vou vender o mercado, e agilizar uma casa próximo do aeroporto, pra que eu de prosseguimento na minha empresa, eu vou abrir uma outra empresa e vou recomeçar do zero." (E1)

Aparentemente, pode-se dizer que as competências saber engajar-se, saber comprometer-se e saber assumir responsabilidades, assim como assumir riscos foram identificadas nos três períodos analisados - antes, durante e depois do insucesso empresarial - representando um aspecto relevante para a superação da adversidade por parte do empreendedor.

\section{4 Saber aprender e ter visão estratégi- ca}

Perante um cenário imprevisível, ter capacidade de visualizar um futuro diferente do presente faz-se necessário para tentar distinguir quais competências serão necessárias para competir em uma nova realidade (NISEMBAUM, 2000). Nessa perspectiva, ter visão estratégica para identificar novas oportunidades no mercado parece ser um fator relevante, como se pode observar no trecho da fala de E4. Este entrevistado demonstrou ter visão estratégica no momento em que viu uma oportunidade no mercado que ainda era pouco explorada. Ressalta-se que este trecho representa o comportamento da maioria dos entrevistados no período antes do insucesso empresarial.

\footnotetext{
"Na época que eu fui empregado, visualizando as opções de crescimento e a experiência positiva dos meus patrões e a oportunidade que surgiu no mercado, pra eu ta entrando, acho que ai eu senti no momento e falei é agora, vou entrar por que acho que é a minha vez. Nesse período, a informática era uma coisa muito nova, essa parte de eletrônica, então eu tava com o pessoal bom, tava saindo da faculdade, então vamos montar um escritório de representação, na parte de design eletrônico, era uma novidade, começou ai a dar certo a coisa $[\ldots]$ " (E4)
} 
Nesse sentido, Paiva Júnior, Leão e Mello (2003) relatam que o empreendedor deve ter capacidade de identificar cenários que convirjam com os objetivos organizacionais, identificando oportunidades, por meio da sua visão, transformando-as em situações positivas para a organização. Embora essa competência tenha sido identificada no momento antes do insucesso empresarial, pode-se perceber que durante o insucesso este foi um aspecto não tão freqüente entre os empreendedores entrevistados, sendo que o trecho da fala de E5 exemplifica esse aspecto.

“[...] Sabia que tem um potencial para crescer, mas não vigiava assim, em cima dessas oportunidades, não vigiava em cima do que acontecia. É, fui aprendendo que às vezes que você tem para segurar está tão perto de você e você corre para outros ângulos, e termina quebrando." (E5)

Dias et al. (2008) resgatam a importância da competência no que tange os aspectos estratégicos adotados pela organização, pois isso poderá refletir no desenvolvimento da competitividade da mesma. Sendo assim, pode-se dizer que, com base nos relatos dos entrevistados, a ausência da visão estratégica pode ser um fator que contribuiu para o insucesso empresarial, como no caso do entrevistado E5 apresentado acima. No entanto, assim como pode ser um fator de risco para o negócio, a visão estratégica também pode emergir como um aspecto que contribui para que o empreendedor que vivenciou o insucesso consiga superar tal adversidade e aprender com a experiência, como evidencia a fala de E6, após o insucesso.

\footnotetext{
"Bom, eu consegui... eu sou uma pessoa muito otimista. Sempre consegui da a volta por cima com tudo que fiz na vida. É aquele negocio que transformava o erro, num acerto, enfim, e fomos melhorando, melhorando, e ai eu, quando vendi, sempre tive o cuidado de reduzir o meu padrão de vida, as circunstancias do momento. E aí fui vendo e me sai bem, estou vivo ate hoje." (E6)
}

Ressalta-se que a aprendizagem aparentemente está atrelada ao comportamento resiliente, o que evidencia uma possível nova abordagem no que diz respeito às competências do empreendedor, principalmente diante de uma adversidade, como no caso do insucesso empresarial. Dessa forma, o comportamento resiliente - considerado como "a habilidade de perceber a realidade a partir do estabelecimento de significados para a situação adversa, aproveitar essa situação para desenvolver-se, aprender com os acontecimentos e situações de crise vivenciadas e estabelecer um conjunto de estratégias (coping) adequadas para superar a adversidade" (MINELLO, 2010, p. 52) - associado ao conceito de aprendizagem, pode ser considerado como uma competência.

\section{Considerações finais}

A partir dos relatos dos entrevistados, pode-se afirmar que há uma relação entre as competências dos empreendedores com a competência da organização, uma vez que as organizações não vivem sem a expertise das pessoas e as pessoas, por sua vez, sem as da organização. A agregação de valor dos indivíduos é portanto uma contribuição para a efetividade da organização, o que lhe permite manter suas vantagens competitivas ao longo do tempo (RUANO, 2003).

Nesse sentido, sugere-se a partir das categorias definidas a priori, que as competências de indivíduos empreendedores que vivenciaram o insucesso empresarial, aparentemente influenciaram no desempenho de seus empreendimentos. Isto pode ser evidenciado pela análise dos resultados dessas categorias antes, durante e depois do insucesso empresarial.

Com relação a primeira categoria, "saber agir e saber comunicar" (FLEURY e FLEURY, 2001), percebeu-se uma preocupação do empreendedor com foco nos 

sarial

resultados do seu negócio. No período anterior ao insucesso, as ações eram voltadas para aproveitar novas oportunidades por meio de sua qualificação e redes de relacionamento. No período durante o insucesso, os empreendedores parecem ter utilizado suas competências para minimizar os efeitos do fracasso empresarial. Já no período posterior, as competências destacaram-se como uma forma de buscar alternativas para superar essa adversidade.

A competência "saber mobilizar recursos" (FLEURY e FLEURY, 2001), abrangeu tanto recursos pessoais quanto financeiros. Anteriormente ao insucesso, foi evidenciada como competência, a formação para gerir os recursos da organização, não identificada na maioria dos empreendedores. Durante e após o insucesso, se destacou a preocupação com os recursos financeiros.

$\mathrm{Na}$ categoria, "saber engajar-se, comprometer-se e assumir responsabilidades" (FLEURY e FLEURY, 2001), foram identificadas competências nos três períodos analisados - antes, durante e depois do insucesso empresarial. Ressalta-se que tais competências apresentaram-se de formas distintas nos três momentos, sendo que no período anterior se destacou o comprometimento com suas ações. Durante o insucesso empresarial, o destaque foi para o desenvolvimento relacionado às suas responsabilidades pelas consequências de seus atos. E após o insucesso, a competência mais frequentemente evidenciada pelos entrevistados foi assumir riscos, como tentativa de reconstruir sua vida profissional.

Por fim, na categoria, "saber aprender e ter visão estratégica" (FLEURY e FLEURY, 2001), no período anterior ao insucesso, pode-se identificar essas competências na maioria dos empreendedores entrevistados. No entanto, durante o insucesso empresarial, essas competências não se manifestaram com tanto destaque. Já no período após o insucesso, observou-se que as competências emergiram novamente, indicando, aparentemente, que as mesmas contribuíram para a superação da adversidade do insucesso empresarial, caracterizando um comportamento resiliente positivo.

O resultado desta categoria parece sugerir um novo escopo de análise que introduz o comportamento resiliente como uma competência do empreendedor. Isso se deve ao fato de os empreendedores terem vivenciado uma situação de adversidade e superado por meio desse comportamento. Ressalta-se então, a possibilidade de novas pesquisas com uma abrangência maior, sugerindo o comportamento resiliente como uma das competências necessárias para os empreendedores atuarem de forma mais adequada diante das adversidades, características do mundo dos negócios. No entanto, como limitação destacase o fato de se tratar de uma pesquisa qualitativa em que não se pode generalizar os dados. Outro aspecto limitador diz respeito a este artigo ter o olhar somente nas competências do empreendedor, sendo que outras variáveis também podem contribuir para o desempenho de seu negócio e consequentemente de seu sucesso ou insucesso.

\section{Referências}

BARDIN, L. Análise de conteúdo. São Paulo: Edições 70, 2011.

BRUNO A. V.; McQUARRIE, E. F.; TORGRIMSON, C. G. The evolution of new technology ventures over 20 years: patterns of failure, merger and survival. Journal of Business Venturing, v. 7, p. 291-302, 1992.

BUENO, A. M.; LEITE, M. L. G.; PILATTI, L. A. Empreendedorismo e comportamento empreendedor: como transformar gestores em empreendedores. Enegep 2004 - XXIV Encontro Nacional de Engenharia de Produção. Florianópolis. Anais, Nov. 2004. 
CARDON, M. S.; FOO, M. D.; SHEPERD D.; WIKLUND, J. Exploring the heart: entrepreneurial emotion is a hot topic. Entrepreneurship Theory and Practice, Jan, p. 1-10, 2012.

DOTLICH, D. L.; CAIRO, P. C. Por que os executivos falham? Rio de Janeiro: Elsevier, 2003.

DORNELAS, J. C. A. Empreendedorismo: transformando idéias em negócios. 3 Ed. Rio de Janeiro: Elsevier, 2008.

DUTRA, J. S. Gestão de pessoas com base em competências. In: DUTRA, J. S. (Org.). Gestão por competências. 2ed. São Paulo: Gente, 2001.

DUTRA, J. S. Competências: Conceitos e Instrumentos para a Gestão de Pessoas na Empresa Moderna. São Paulo: Atlas, 2004.

DIAS, G. B.; BECKER, G. V.; DUTRA, J. S.; RUAS, R.; GHEDINE, T. Revisando a noção de competência na produção científica em administração: avanços e limites. In.: DUTRA, J. S.; FLEURY, M. T.; RUAS, R. Competências: conceitos, métodos e experiências. São Paulo: Atlas, 2008.

FILION, L. J. Empreendedorismo: empreendedorismo e proprietários-gerentes de pequenos negócios. Revista de Administração de Empresas. v. 34, n. 2, p. 05-28, abr-jun. São Paulo, 1999.

FILION, L. J.; LIMA, E. As representações empreendedoras: importantes temas para avançar em seu estudo. Revista de Negócios, Blumenau. v. 15, n. 2, p.32-52, abr-jun, 2010.

FINKELSTEIN, S. Por que executivos inteligentes falham. São Paulo: Makron Books, 2007.

FLECK, D. Archetypes of Organizational Success and Failure. Brazilian Administration Review (BAR), v. 6, n. 2, art. 1, p. 78-100, April/June. Curitiba, 2009.

FLEURY, M.T.L. e FLEURY A. Construindo o conceito de competência. Revista de Administração Contemporânea. V. 5, p. 183-196. Edição Especial. Curitiba, 2001a.

GEM. Empreendedorismo no Brasil. Global Entrepreneurship Monitor, publicada em Curitiba, 2010.

HISRICH, R. D.; PETERS, M. P.; SHEPHERD, D. A. Empreendedorismo. 7 Ed. Porto Alegre: Bookman, 2009.

LE BOTERF, G. Évaluer le compéteces: quels jugements? quels critères? quelles instances? Education Permanent, n. 135, 1998.

LENZI, F. C. Os empreendedores corporativos nas empresas de grande porte dos setores mecânico, metalúrgico e de material elétrico/ comunicação em Santa Catarina: um estudo da associação entre tipos psicológicos e competências empreendedoras reconhecidas. Tese de Doutorado. (Programa de Pós-Graduação em Administração) - Faculdade de Economia, Contabilidade e Administração. Universidade de São Paulo. São Paulo, 2008.

MINELLO, I.F. Resiliência e insucesso empresarial: um estudo exploratório sobre o comportamento resiliente e os estilos de enfrentamento do empreendedor em situações de insucesso empresarial, especificamente em casos de descontinuidade do negócio. Tese de Doutorado. (Programa de Pós-Graduação em Administração) Faculdade de Economia, Contabilidade e Administração. Universidade de São Paulo. São Paulo, 2010.

MUSSAK, E. Metacompetência: uma nova visão do trabalho e da realização pessoal. $3^{a}$ ed. São Paulo: Gente, 2003.

NISENBAUM, H. A competência essencial. São Paulo: Infinito, 2000.

PAIVA JUNIOR, F. G.; LEÃO, A.L.M.S.; MELLO, S.C.B. Competências Empreendedoras em Comportamentos de Dirigentes de Êxito Socialmente Reconhecido. In: XXVII Encontro Nacional dos Programas 
Competências do empreendedor: Uma análise com empreendedores que vivenciaram o insucesso empresarial

de Pós-Graduação em Administração, 27, 2003. Atibaia. Anais... São Paulo: ANPAD, 2003.

PEREIRA, H. J. Motivos de sucesso e de fracasso empresarial. In: Criando seu próprio negócio: como desenvolver o potencial empreendedor. Coordenação de Heitor José Pereira e Silva Aparecido dos Santos. Brasília: Ed. SEBRAE, p. 271278, 1995.

ROBINSON, S. Business failure rates: a look at sex and location. Academy of Entrepreneurship Journal. v.13, n.1, p. 45, 2007.

RUANO, A. M. Gestão por Competências: uma perspectiva para a consolidação da gestão estratégica de recursos humanos. Rio de Janeiro: Qualitymark; São Paulo: ABRH-Nacional, 2003.

SAMPIERI, R. H.; COLLADO, C. F.; LUCIO, P. B. Metodologia de Pesquisa.

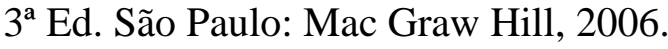

SHEPHERD, D. A. Learning from business failure: propositions of grief recovery for the selfemployed. Academy of Management Review, v. 28, n. 2, p. 318-328, 2003.

SHEPHERD, D.A.; CARDON, M.S. Negative emotional reactions to project failure and the selfcompassion to learn from the experience. Journal of Management Studies, v. 46, p. 923-949, 2009.

SINGH S.; CORNER, P.; PAVLOVICH, $\mathrm{K}$. Coping with entrepreneurial failure. Journal of Management \& Organization; v. 13, p. 331-344, 2007.

UCBASARAN, D.; WESTHEAD, P.; WRIGHT, M.; FLORES, M. The nature of entrepreneurial experience, business failure and comparative optimism. Journal of Business Venturing. v. 25, p. 541-555, 2010.

ZACHARAKIS, A. L.; MEYER, G. D.; DECASTRO, J. Differing perceptions of new failure: a matched exploratory study of venture capitalists and entrepreneurs. Journal of Small Business Management; v. 37, n. 3; p. 1-19, 1999.

ZARIFIAN, P. Objetivo Competência: por uma nova lógica. São Paulo: Atlas, 2001. 